OPEN ACCESS

Edited by:

Abad Chabbi,

INRA Centre

Versailles-Grignon, France

Reviewed by:

Ingo Schöning,

Max Planck Institute for

Biogeochemistry, Germany

Carsten W. Mueller,

University of Copenhagen, Denmark

${ }^{*}$ Correspondence:

Derek Pierson

piersond@oregonstate.edu

Specialty section:

This article was submitted to

Soil Processes,

a section of the journal

Frontiers in Environmental Science

Received: 17 January 2020

Accepted: 15 March 2021

Published: 09 April 2021

Citation:

Pierson D, Peter-Contesse $H_{\text {, }}$

Bowden RD, Nadelhoffer K, Kayhani K, Evans L and Lajtha $K$ (2021) Competing Processes Drive

the Resistance of Soil Carbon to

Alterations in Organic Inputs.

Front. Environ. Sci. 9:527803.

doi: 10.3389/fenvs.2021.527803

\section{Competing Processes Drive the Resistance of Soil Carbon to Alterations in Organic Inputs}

\author{
Derek Pierson ${ }^{1 *}$, Hayley Peter-Contesse ${ }^{1}$, Richard D. Bowden ${ }^{2}$, Knute Nadelhoffer ${ }^{3}$, \\ Kamron Kayhani ${ }^{1}$, Lucas Evans ${ }^{1}$ and Kate Lajtha ${ }^{1}$
}

${ }^{1}$ Department of Crop and Soil Sciences, Oregon State University, Corvallis, OR, United States, ${ }^{2}$ Department of Environmental Science and Sustainability, Allegheny College, Meadville, PA, United States, ${ }^{3}$ Department of Ecology and Evolutionary Biology, University of Michigan, Ann Arbor, MI, United States

Protecting existing soil carbon $(\mathrm{C})$ and harnessing the $\mathrm{C}$ sequestration potential of soils require an improved understanding of the processes through which soil organic matter accumulates in natural systems. Currently, competing hypotheses exist regarding the dominant mechanisms for soil C stabilization. Many long-standing hypotheses revolve around an assumed positive relationship between the quantity of organic inputs and soil $\mathrm{C}$ accumulation, while more recent hypotheses have shifted attention toward the complex controls of microbial processing and organo-mineral complexation. Here, we present the observed findings of soil response to 20 years of detrital manipulations in the wet, temperate forest of the H.J. Andrews Experimental Station. Annual additions of low-quality (high C:N content) wood litter to the soil surface led to a greater positive effect on observed mean soil $\mathrm{C}$ concentration relative to additions of higher-quality (low $\mathrm{C}: \mathrm{N}$ content) needle litter over the 20-year study period. However, high variability in measurements of soil $\mathrm{C}$ led to a statistically non-significant difference in $\mathrm{C}$ concentration between the two treatments and the control soil. The observed soil $\mathrm{C}$ responses to these two addition treatments demonstrates the long timescale and potential magnitude of soil $\mathrm{C}$ responses to management or disturbance led changes in forest litter input composition. Detrital input reduction treatments, including cutting off live root activity and the aboveground removal of surface litter, led to relatively small, non-significant effects on soil $\mathrm{C}$ concentrations over the 20-year study period. Far greater negative effects on mean soil $\mathrm{C}$ concentrations were observed for the combined removal of both aboveground litter and belowground root activity, which led to an observed, yet also non-significant, $20 \%$ decline in soil $\mathrm{C}$ stocks. The substantial proportion of remaining soil $\mathrm{C}$ following these dramatic, long-term reductions in above- and belowground detrital inputs suggests that losses of $C$ in these forest soils are not readily achieved over a few decades of reductions in detrital input and may require far greater periods of time or further perturbations to the environment. Further, the observed soil $\mathrm{C}$ responses to detrital manipulations support recent hypotheses regarding soil C stabilization, which emphasize litter quality and mineral stabilization as relevant controls over forest soil C.

Keywords: soil carbon, stabilization, destabilization, litter, roots, forest, long-term, detritus 


\section{INTRODUCTION}

Soils represent the most significant long-term organic carbon (C) reservoir in terrestrial ecosystems, and forest soils account for almost $40 \%$ of soil C stored globally (Janzen, 2004). As we face potentially rapid changes in forest environments from increasing disturbances and shifting climates (Kirilenko and Sedjo, 2007; Morris, 2010), the response of forest soil C stocks remains a critical unknown in our efforts to predict future effects on atmospheric $\mathrm{C}$ concentrations, forest ecosystems, and associated natural resources (Ziegler et al., 2017). In recent years, considerable knowledge gains have been made regarding how specific, individual environmental conditions and soil properties may affect soil C stabilization processes. Yet, we continue to lack a robust understanding of how these unique biogeochemical influences may interact in natural environments to regulate the turnover and stabilization of soil C (e.g., Campos et al., 2017; Chen et al., 2017, 2018; Harden et al., 2018). Across, as well as within diverse forest ecosystems, numerous questions remain regarding how specific combinations of organic matter input quantity and quality, climate, soil mineralogy, and microbial community properties coalesce to control soil C stocks (Davidson et al., 2000; Crow et al., 2009; Cotrufo et al., 2013; Fekete et al., 2014; Lajtha et al., 2014a). Further, we have yet to broadly determine whether common relationships in soil C processing factors exist across unique forest types vs. areas where greater knowledge of site-specific factors and relationships will be necessary to unravel and predict soil $\mathrm{C}$ responses. To answer these questions and improve the understanding of the ecosystem scale of soil C dynamics, we require further direct studies of soil C stabilization and sensitivities in diverse natural forest environments (Davidson and Janssens, 2006).

Forest environments provide an opportunity to mitigate rising atmospheric $\mathrm{C}$ concentrations through altered land use and management practices which promote $\mathrm{C}$ sequestration (Griscom et al., 2017). Studies aimed at increasing forest $C$ sequestration have largely focused on vegetation, delving into the potential avenues for increasing forest productivity, and subsequently storing greater amounts of $\mathrm{C}$ in plant biomass (McKinley et al., 2011; Pan et al., 2011; Post et al., 2012). However, the associated effects on soil C stocks have not been well-characterized. As increases in forest productivity will drive subsequent increases in detrital inputs to forest soils, resulting changes in soil C may serve to either aid or potentially hinder total $\mathrm{C}$ sequestration gains. Assumptions of a positive linear relationship between detrital input quantity and soil $\mathrm{C}$ have long been prevalent and remain commonplace in popular ecosystem models of $\mathrm{C}$ cycling (Liski et al., 2002; Gottschalk et al., 2012). However, recent studies have demonstrated such a relationship may not be universal across forest ecosystems (Lajtha et al., 2018). Priming effects, where the addition of fresh organic material promotes microbial activity resulting in the destabilization of previously stored soil C, offers a potential explanation for a reduced or negative soil $\mathrm{C}$ response to increases in detrital input quantity (Fontaine et al., 2004; Kuzyakov, 2010; De Graaff et al., 2014; Sulman et al., 2014; Cardinael et al., 2015; Georgiou et al., 2015; Keiluweit et al., 2015; Kuzyakov and Blagodatskaya, 2015;
Finley et al., 2018; Jackson et al., 2019). However, the longevity and the potential magnitude of priming effects on forest soil $\mathrm{C}$ stocks are less well-characterized. Priming effects are likely to have disproportionate impacts on soil C stabilization across disparate environments, as litter quantity, soil organic matter (SOM) decomposition rates, and soil C stocks vary substantially across forest soils. Increases in soil $\mathrm{C}$ may also be limited by the capacity of a given soil matrix to retain and stabilize soil organic carbon (SOC), as differing soil types may provide a greater or worse abundance of reactive mineral surfaces allowing for organo-mineral complexations (Stewart et al., 2008; Chung et al., 2010; Beare et al., 2014; Mayzelle et al., 2014; Castellano et al., 2015). In our efforts to identify future environments and practices which provide an opportunity to improve $\mathrm{C}$ sequestration in forest systems, it remains essential to enhance our understanding of both the common and disparate factors that regulate soil C stabilization.

Recent studies of soil C stabilization have placed renewed emphasis on the role of detrital input quality, which may be defined as the elemental ratio between $\mathrm{C}$ and the limiting nutrients in an organic compound. The quality of organic matter inputs has been widely hypothesized to influence soil $\mathrm{C}$ accumulation and stabilization by altering microbial activity, processing pathways, and carbon use efficiencies (Cotrufo et al., 2013). Increases in carbon use efficiency and microbial products are expected when substrate quality approaches the elemental composition of microbial biomass, as the limiting nutrients required for microbial processes are more readily available. Analyses of the molecular nature of stabilized SOC show a close resemblance between microbial products and the organic material bound to mineral matrices (Amelung et al., 2008; Miltner et al., 2012; Gleixner, 2013; Kallenbach et al., 2016). As leaf or needle litter is often of much higher quality (low $\mathrm{C}: \mathrm{N}$ ) than sources of woody debris (high $\mathrm{C}: \mathrm{N}$ and higher lignin:N), we would expect a greater proportion of needle litter $\mathrm{C}$ to be stabilized in the soil relative to the $\mathrm{C}$ from woody debris. While root material and exudates are often of high molecular quality, their location in the mineral soil provides a further advantage for subsequent stabilization of SOC. Linkages between SOC, root mass, and root chemical properties have been broadly reported across forest and agricultural soils (Rasse et al., 2005; Kätterer et al., 2011; Melillo et al., 2011; Angst et al., 2019). However, only a few studies have examined the potential difference in the relationship between roots and soil $\mathrm{C}$ accumulation vs. soil $\mathrm{C}$ persistence. Further understanding of how differences in the source and quality of detrital material influence microbial decomposition pathways and the potential for soil C stabilization is critical as we seek to resolve how changes in forest environments may alter soil C stocks.

The pathways and controls dictating the processes of soil C stabilization may differ from those that govern soil C destabilization (Bailey et al., 2019). Consequently, reversing or limiting the processes and conditions found to give rise to gains in soil C may not inherently lead to a loss of soil C. This concept is of paramount importance when studying processes of mineral stabilization, as the conditions which give rise to an organo-mineral interaction may be vastly different from 
those required to allow for the cleavage of organic molecules from mineral surfaces. Similar to the uncertainty regarding how detrital additions may increase soil $\mathrm{C}$, we also continue to lack a clear understanding of the timescale and potential influences detrital quantity and quality may have on soil $\mathrm{C}$ destabilization (Sollins et al., 2007).

The Detrital Input and Removal Treatment (DIRT) network was established to study the long-term effects of altered aboveand belowground detrital inputs on soil $\mathrm{C}$ in natural forest environments (Nadelhoffer et al., 2004; Lajtha et al., 2018). This study presents findings following 20 years of a DIRT experiment in the wet temperate forest of the H.J. Andrews Experimental Forest (HJAF). The HJAF DIRT experiment is unique among sites in the DIRT network, as it is the first conifer forest site to study detrital effects on soil C over two decades. The HJAF DIRT is also the most productive forest type in the network, with the greatest stocks of soil C. As such, we expect soil C responses to the detrital treatments at HJAF to differ from those previously observed at other sites in the network. Further, the HJAF DIRT experiment is the first in the DIRT network to study the effects of detrital surface additions with differing quality, using two separate treatments which increase the surface input of either needle litter or wood debris. Previous studies of detrital material at the HJAF DIRT study site have shown that the C:N content of the needle litter is $\sim 8$ times lower than the Douglas fir wood material, both when fresh and after many years of decomposition (Yano et al., 2005). Molecular composition differences are also abundant between the two litter materials, as Douglas fir wood contains $\sim 3$ times more lignin and cellulose than needle litter, while needle litter has a greater concentration of tannins, which may slow protein degradation (Horner et al., 1987; Means et al., 1992; Valachovic et al., 2004). Phenolic compounds and compounds with high molecular complexity such as lignin and cellulose have been widely recognized for longer decomposition timescales relative to simpler and more nutrient-rich litter material (Preston et al., 2009; Talbot and Treseder, 2012; Talbot et al., 2012). The intent for the inclusion of disparate additional treatments in the HJAF DIRT experiment was to observe how the substantial contrasting qualities of these two common detrital materials affect soil C. Such novel information will help to inform further studies of quality influences on soil C stabilization and improve the modeling of detrital input effects on SOM decomposition pathways and timescales.

The objectives of the following study were to determine the effect of sustained detrital additions of differing quality on soil C accumulation, as well as the sensitivity of soil C to reductions in organic substrate inputs from above- and belowground sources. We hypothesized that: (1) High-quality litter additions would lead to greater increases in mineral soil $\mathrm{C}$ relative to the lowquality wood debris additions. However, the addition of wood debris would result in larger increases of organic material in the organic soil horizon due to slow decomposition rates; (2) Root exclusions would cause greater decline in soil C than the reduction in aboveground inputs; (3) Exclusion of both aboveand belowground detrital inputs to soils would result in a far greater loss of soil $\mathrm{C}$ relative to soils subject to either root or aboveground litter exclusion.

\section{METHODS}

\section{Site Description}

The DIRT experiment was established at the H.J. Andrews Experimental Forest in the Western Cascade Mountain region of Oregon, USA $\left(44^{\circ} 15^{\prime} \mathrm{N}, 12^{\circ} 10^{\prime} \mathrm{W}\right)$. The climate is Mediterranean, with warm, dry summers and cool, wet winters, which yield the majority of annual precipitation as a rain-snow mix between December and April. Mean annual precipitation at the site is $2,080 \mathrm{~mm} \mathrm{yr}^{-1}$ and the mean annual temperature is $9.4^{\circ} \mathrm{C}$ (average from years 1999 to 2014). According to the U.S. Department of Agriculture soil classification system (Soil Survey Staff, 1999), the underlying soils at the DIRT experiment site are a mix of coarse loamy mixed mesic Typic Hapludands (Lajtha et al., 2005) and Andic Dystrudepts (Aluandic Andosol classified by WRB). The south-facing study site lies at an elevation of $726 \mathrm{~m}$. Slopes of $<5 \%$ steepness are consistent across the site. Erosion and overland flow are minimal, largely impeded by the gentle slopes and a thick $(4-8 \mathrm{~cm})$ organic soil horizon. The dominant overstory is mixed old-growth Douglas fir (Pseudotsuga menziesii) and Western Hemlock (Tsuga heterophylla), with a smaller mix of Western Red Cedar (Thuja plicata), Vine Maple (Acer circinatum), and Big-Leaf Maple (Acer macrophyllum). Large amounts of woody debris, overturned stumps, and fallen logs are strewn across the forest floor due to the mature stand age and propensity for the shallow-rooting Douglas fir to topple from wind and snow burden.

\section{Experimental Design}

The DIRT experiment at the H.J. Andrews Forest was initially established in 1997 and includes six detrital input treatments (Table 1). All study plots were installed in a single area with uniform topography and forest vegetation characteristics. Each treatment was applied to individual plots and there were three plot replicates per treatment, which were randomly distributed across the study site to account for any underlying variability in soil or vegetation properties. Plot sizes for all treatments except the No Root (NR) and No Input (NI) plots are $\sim 150 \mathrm{~m}^{2}$, while the NR and NI plots range from 55 to $75 \mathrm{~m}^{2}$. For the No Litter (NL) treatment, mesh screens were placed along the soil surface and used to collect and remove all aboveground litter from the plots on an annual basis. The 1-mm screen mesh allows for water and gas exchange while preventing the majority of litterfall from interacting with the soil surface. The Double Litter (DL) treatment was performed by adding the litter removed from the NL plots to the surface of plots receiving natural litterfall. The additional litter was manually spread across the plot surface to achieve a total annual litterfall rate equal to twice the litter mass per area measured during the litter removal in the NL plot. The Double Wood (DW) treatment was similarly applied by manually spreading a thin layer of Douglas fir wood chips across otherwise natural plots at a rate equivalent to the mass of annual litterfall. The NR treatment was performed by lining a 1-m deep trench around each plot with a thick plastic material and backfilling in such a manner that the incoming roots are directed down and away from the plot. Live trees within the NR plot border were girdled when the experiment was initiated 
TABLE 1 | Description of detrital manipulation treatments.

\begin{tabular}{|c|c|c|}
\hline Treatment & Abbreviation & Description \\
\hline Control & CTL & Natural above- and belowground detrital inputs \\
\hline Double litter & $\mathrm{DL}$ & $\begin{array}{l}\text { Aboveground needle and leaf litter inputs } \\
\text { doubled annually* }\end{array}$ \\
\hline Double wood & DW & $\begin{array}{l}\text { Double wood debris applied every other year as } \\
\text { wood chips }{ }^{\star \star}\end{array}$ \\
\hline No litter & $\mathrm{NL}$ & $\begin{array}{l}\text { Aboveground inputs removed annually in late fall } \\
\text { season }\end{array}$ \\
\hline No roots & NR & $\begin{array}{l}\text { Live roots excluded via 0-140 cm tarp-lined } \\
\text { trenches around plots }\end{array}$ \\
\hline No input & $\mathrm{NI}$ & $\begin{array}{l}\text { Aboveground inputs excluded as in no-litter } \\
\text { plots, belowground inputs prevented as in } \\
\text { no-roots plots }\end{array}$ \\
\hline OA-less & NOA & $\begin{array}{l}\text { Top } 30 \mathrm{~cm} \text { of soil (O and } \mathrm{A} \text { Horizons) replaced } \\
\text { with mineral soil }\end{array}$ \\
\hline
\end{tabular}

*Additional litter supplied from the litter exclusion plots and allocated proportionally. ${ }^{\star}$ Wood addition mass estimated to equal falling wood debris in the control plots.

to prevent root growth and activity. The NI treatment involved the combination of litter screens and trenching as performed for the NL and NR treatments. Finally, the No Organic and A-horizon treatment (NOA) was performed by mechanically removing the topsoil to a depth of $30 \mathrm{~cm}$, then backfilling with Bhorizon material sourced from a hillslope immediately adjacent to the experimental area. Undisturbed Control (CTL) plots were defined when the experiment was initiated. All treatment applications for the DL, DW, NL, and NI treatments were applied annually in the late summer months. Natural litterfall input to plot surfaces, as was determined from the average mass of needle litter removed from the NL and NI plots each year, was remarkably consistent, measuring $293 \pm 29 \mathrm{~g} \mathrm{~m}^{-2} \mathrm{yr}^{-1}$.

\section{Soil Sampling}

Soils were sampled in July 2017 after 20 years of sustained treatment applications. Samples for soil bulk density were collected first so as to determine how the soil surface may have expanded or compacted from the applied experimental treatments. At three random locations in each plot, a polyvinyl chloride (PVC) tube with a diameter of $5.4 \mathrm{~cm}$ and a height of $15 \mathrm{~cm}$ was gently inserted into the mineral soil surface. After installation, we measured the difference in distance from the top of the installed PVC tube to the outer soil surface and the inner soil surface. Differences were consistently $<1 \mathrm{~cm}$, allowing us to confirm that minimal compaction occurred during the PVC tube installations. Due to the conducive soil texture and moisture, we were then able to remove the PVC tubes along with intact soil cores down to a depth of $15 \mathrm{~cm}$.

From each plot, mineral soil samples were collected at six randomly chosen locations. The soil organic layer was collected by removing a $150-\mathrm{cm}^{2}$ area of the forest floor down to the mineral soil surface. No evident amount of soil organic horizon remained on the NL and NI plots. Starting below the organic layer at each sampling location, mineral soil samples were subsequently collected at specific depth increments, including
$0-10,10-20,20-40,40-60 \mathrm{~cm}$. Soil samples from a depth of 60 $100 \mathrm{~cm}$ were also collected at two of the six sampling locations per plot, as sampling to such depth was labor-intensive and we expected variability in soil properties to be far less at greater soil depths. Samples from the depths of $0-10$ and $10-20 \mathrm{~cm}$ were collected using an Oakfield-style soil core sampler (Oakfield Apparatus Co. Fond du Lac, Wisconsin) with a diameter of $5.8 \mathrm{~cm}$. A $5.1 \mathrm{~cm}$ diameter soil auger with a $12 \mathrm{~cm}$ soil collection bucket was used to collect samples at depths beyond $20 \mathrm{~cm}$.

\section{Soil Analysis}

In the laboratory, the bulk density soil cores, still shrouded in the PVC tube casing, were cut with a fine-cut hacksaw to isolate the core section representing exactly $0-10 \mathrm{~cm}$ soil depth. All soil material was then removed from the core, dried at $105^{\circ} \mathrm{C}$, and weighed to determine the dry mass per volume of the soil. For the few samples which contained large rocks, the bulk density was corrected by subtraction of both the rock mass and volume from the bulk density calculation. The volume of the rock was determined by water displacement. Soils from the bulk density analysis were not included in any other analyses performed in the study.

Soil organic horizon material was dried at $60^{\circ} \mathrm{C}$ and weighed to determine the organic horizon mass per area for each sample. These mass values of the samples were then combined to determine the average organic horizon mass per area for each plot. After compositing and grinding the litter samples from each plot, the $\mathrm{C}$ and $\mathrm{N}$ content of the material was determined using an Elementar Vario Macro Cube (Elementar Analysensysteme $\mathrm{GmbH}$, Langenselbold, Germany). During treatment application in the fall of 2017, six individual samples of needle litter were collected from the surface of the removal plot screens to determine the $\mathrm{C}$ and $\mathrm{N}$ content of the litter material applied to the DL plots. Similarly, six replicate samples of the wood chip material were collected for analysis. Respectively, the C concentration for the needle litter and wood chips were 459 \pm 3 and $472 \pm 1 \mathrm{mg} \mathrm{C} \mathrm{g}^{-1}$, with C:N ratios of $46.6 \pm 2.2$ and $117 \pm 8.7$.

Mineral soil samples from each plot and depth increment were separately sieved to $2 \mathrm{~mm}$ and allowed to air-dry for 6 weeks. The roots removed by the sieve, as well as those manually removed after sieving, were grouped by their diameter, i.e., greater or lesser than $2 \mathrm{~mm}$ and then gently cleaned, dried, and weighed. We did not expect the core sampling method to provide for an accurate estimation of large roots in the plots as the core samplers were unable to easily cut through roots larger than $\sim 10 \mathrm{~mm}$. Thus, we have limited the reports of root mass in this study to only the fine roots, which are $<2 \mathrm{~mm}$ in diameter. Composite mineral soil samples were made for each depth increment by combining an equal mass of the sieved mineral soils from each of the replicate samples taken within each plot. The composite soil samples by plot and depth were used for all chemical analyses performed in the study. The composite mineral soil and organic horizon samples were finely ground before analysis of total percent $\mathrm{C}$ by dry combustion using an Elementar Vario Macro Cube (Elementar Analysensysteme $\mathrm{GmbH}$, Langenselbold, Germany). The accuracy of the $\mathrm{C}$ analysis 
was confirmed by $>90 \%$ accuracy of the included standard reference samples and $>90 \%$ consistency in the analysis results between sample replicates. The soil $\mathrm{pH}$ was determined on mineral sample composites obtained from only a depth of 0 $10 \mathrm{~cm}$ in a $1: 2$ soil/solution using $0.01 \mathrm{M} \mathrm{CaCl}_{2}$ slurry. The soil C stocks for each plot were calculated by multiplying the percentage of composite soil C by the corresponding soil bulk density for each depth increment. The depth increments for the mineral soil surface were adjusted to account for equivalent soil mass since changes in organic material incorporation, not mineral mass loss, were attributed to causing observed changes in bulk density.

From October 2017 through November 2018, the soil $\mathrm{CO}_{2}$ efflux was measured roughly every week in May to July and once per month during the remainder of the year using a portable infrared gas analyzer (IRGA) (LI-8100A; LI-COR Inc., Lincoln, $\mathrm{NE}$ ) attached to a closed dynamic respiration chamber (LI-8100102; LI-COR Inc.) placed over a $10 \mathrm{~cm}$ diameter PVC collar. Each PVC collar measured $5 \mathrm{~cm}$ in height and was inserted $2 \mathrm{~cm}$ into the mineral soil. Three PVC collars were permanently installed in each plot, and collar volumes were measured frequently, with updated volumes of collars + chamber headspace used for flux calculations at each collar location. The portable IRGA measured the buildup of $\mathrm{CO}_{2}$ in the collar + chamber headspace over $90 \mathrm{~s}$ and the IRGA purges gas after each measurement. Measurements were typically taken randomly between 0900 and $1300 \mathrm{~h}$ to minimize temporal effects on the $\mathrm{CO}_{2}$ efflux. Seasonal mean soil respiration for each treatment group was computed for spring $(n$ $=36)$, summer $(n=99)$, and fall $(n=63)$, and treatment group mean respiration values were compared with CTL group mean respiration by season (Table 2).

\section{Statistical Analysis}

For the statistical analysis of differences in soil C concentrations and stocks, we performed a one-way ANOVA using the $\mathrm{R}$ statistical software with detrital manipulation treatment as the explanatory variable. Post-hoc Tukey honestly significant difference (HSD) tests were then performed to find significant differences among pairwise combinations of treatments with a standard significance level of $p<0.05$. ANOVA and the posthoc Tukey HSD tests were performed separately by soil depth increment $(0-10,10-20 \mathrm{~cm}$, etc.), as well as for the whole soil profile $(0-100 \mathrm{~cm})$. The statistical significance of mean seasonal respiration differences between the treatment and the CTL soils were similarly tested using a one-way ANOVA and post-hoc Tukey HSD for each seasonal comparison.

\section{RESULTS}

Doubling needle litter (DL) inputs had no significant effect on the soil $\mathrm{C}$ concentration of the mineral soil after 20 years of sustained additions ( $p<0.99$, Figure $1 \mathrm{~A}$, Table 2 ). Throughout the $0-100 \mathrm{~cm}$ soil profile, the $10-20 \mathrm{~cm}$ layer was the only soil depth increment at which any indication of a potential treatmentdriven increase in the soil $\mathrm{C}$ concentration was observed, with a mean difference of $6.7 \mathrm{~g} \mathrm{C} \mathrm{kg}^{-1}$ soil (29\% relative increase) in the soil $\mathrm{C}$ concentration. In contrast, the addition of Douglas fir wood chips (DW) to the soil surface showed a much greater potential for increasing soil C concentrations (Figure 1A,
Table 2). The mean soil C concentrations following the DW treatment were greater than those of the CTL soil throughout the $0-100 \mathrm{~cm}$ soil profile, with mean soil C increases of 24 and $54 \%$ observed at $0-10$ and $10-20 \mathrm{~cm}$, respectively. While substantial, the mean differences between the DW and CTL were not found to be significant $(p<0.91)$ given the relatively large variability in soil $\mathrm{C}$ response that was observed. Replacing the organic and mineral soil horizons observed at $0-30 \mathrm{~cm}$ with Cpoor mineral soil (NOA) had the greatest effect on soil properties at the soil surface $(0-10 \mathrm{~cm})$ relative to the control, with a mean difference in soil C concentration of $26.9 \mathrm{~g} \mathrm{C} \mathrm{kg}^{-1}$ soil $(54 \%$ relative decline). Soil $\mathrm{C}$ concentrations did not recover at the soil surface following the NOA treatment and remained significantly lower than the control $(p<0.01)$. Also, no significant difference between the NOA and CTL soil C concentrations was observed at lower depths $(p<0.99)$.

Depriving soils of surface litter inputs (NL) led to small or negligible declines in mean soil $\mathrm{C}$ concentration across the depth increments sampled from 0 to $100 \mathrm{~cm}(p<0.98$, Figure 1B). Near the soil surface, NL treatment soil C concentrations remained strongly similar to those of the CTL, with mean C concentrations of 47.2 and $49.7 \mathrm{~g} \mathrm{C} \mathrm{kg}^{-1}$ soil, respectively. Greater declines in mean soil C concentration (11-22\%) from the NL treatment were observed at depths beyond $20 \mathrm{~cm}$. However, these observed changes were also not sufficient in magnitude to reach statistical significance $(p<0.98)$. Similar to the NL treatment, cutting off the growth and activity of live roots in the mineral soil (NR) had no significant effect on soil C concentrations at the depth of 0 $10 \mathrm{~cm}$ of mineral soil $(p<0.96)$. However, at $10-20 \mathrm{~cm}$, the NR treatment led to an interesting, yet non-significant $(p<0.98)$, $21 \%$ increase in mean soil C concentration relative to the CTL. We found this trend reversed at greater depths, where the NR treatment mean soil $\mathrm{C}$ concentrations subsequently changed to a non-significant extent by $30 \%$ at $40-60 \mathrm{~cm}$ and $27 \%$ at $60-100 \mathrm{~cm}$ $(p<0.99)$. The no input $(\mathrm{NI})$ treatment, for which both surface litter inputs and live roots were excluded from the soil, was consistently found to have the lowest mean soil C concentration across the three detrital reduction treatments (NL, NR, NI). Similar to the positive response observed from the NR treatment at $10-20 \mathrm{~cm}$, the NI soil $\mathrm{C}$ concentration in the same layer also increased $(+9 \%)$, yet the change was not found to be significant $(p<0.99)$. At depths other than $10-20 \mathrm{~cm}$, declines in mean soil C concentration from the NI treatment were consistently between 17 and $44 \%$ relative to the CTL soil C $(p<0.98)$.

In the surface soils $(0-10 \mathrm{~cm})$, the observed changes in soil bulk density by treatment type coincide precisely with the separate determinations of changes in mean soil $\mathrm{C}$ concentration, as would be expected from the inverse relationship between bulk density and SOM content (Figure 2, Table 2). At a lower depth of $10-15 \mathrm{~cm}$, differences in bulk density across all treatment types were not significant $(p<0.99)$. The observed increase of $0.05 \mathrm{~g}$ $\mathrm{cm}^{-3}$ in the $0-10 \mathrm{~cm}$ DL soil bulk density was not found to be significantly different from the CTL, a finding in agreement with the minimal change observed in the DL soil C concentration at the same depth. In contrast, the mean soil bulk density in the DW treatment was $0.50 \pm 0.08$, compared to $0.61 \pm 0.08$ in the control; yet, high variability in the bulk density measurements resulted in a non-significant statistical difference. Such a decline 
TABLE 2 | Soil carbon (C) concentration, content, root mass, respiration, pH, bulk density, and aboveground litter mass by detrital manipulation treatment type following 20 years of treatment.

\begin{tabular}{|c|c|c|c|c|c|c|c|}
\hline Depth (cm) [Season] & Control [CTL] & Double litter [DL] & Double wood [DW] & No litter [NL] & No roots [NR] & No input [NI] & OA-less [NOA] \\
\hline \multicolumn{8}{|c|}{ Organic $C$ concentration, $g \mathrm{C} \mathrm{kg}^{-1}$ soil } \\
\hline $0-10$ & $49.7 \pm 8.0 \mathrm{a}^{\dagger}$ & $49.4 \pm 10.1 \mathrm{a}$ & $61.8 \pm 12.6 \mathrm{a}$ & $47.2 \pm 5.1 \mathrm{a}$ & $50.6 \pm 5.2 a$ & $41.4 \pm 3.1 \mathrm{a}$ & $22.8 \pm 4.5 b$ \\
\hline $10-20$ & $23.0 \pm 3.2$ & $29.7 \pm 1.8$ & $34.6 \pm 12.2$ & $23.9 \pm 2.7$ & $27.9 \pm 1.1$ & $25.1 \pm 4.4$ & $21.7 \pm 6.2$ \\
\hline $20-40$ & $20.6 \pm 1.2$ & $19.2 \pm 1.7$ & $23.4 \pm 5.1$ & $18.0 \pm 2.4$ & $20.9 \pm 1.7$ & $15.1 \pm 2.9$ & $17.4 \pm 3.2$ \\
\hline $40-60$ & $12.9 \pm 2.1$ & $10.9 \pm 1.2$ & $13.5 \pm 3.6$ & $11.5 \pm 3.0$ & $9.1 \pm 0.6$ & $7.2 \pm 0.6$ & $12.0 \pm 1.2$ \\
\hline $60-100$ & $6.3 \pm 0.9$ & $8.1 \pm 1.6$ & $8.3 \pm 2.3$ & $4.9 \pm 1.2$ & $4.6 \pm 0.6$ & $4.1 \pm 1.0$ & $5.6 \pm 1.0$ \\
\hline \multicolumn{8}{|l|}{ C:N content } \\
\hline $0-10$ & $28.7 \pm 1.8$ & $22.6 \pm 1.4$ & $27.6 \pm 2.1$ & $24.5 \pm 1.5$ & $22.2 \pm 1.4$ & $23.9 \pm 0.8$ & $20.3 \pm 1.3$ \\
\hline $10-20$ & $19.2 \pm 1.2$ & $19.1 \pm 1.4$ & $23.9 \pm 3.8$ & $19.0 \pm 1.2$ & $17.4 \pm 0.8$ & $16.3 \pm 2.6$ & $21.2 \pm 0.7$ \\
\hline $20-40$ & $17.0 \pm 0.7$ & $17.1 \pm 0.3$ & $18.0 \pm 1.0$ & $16.3 \pm 1.2$ & $15.7 \pm 5.2$ & $16.4 \pm 1.7$ & $18.7 \pm 2.5$ \\
\hline $40-60$ & $15.4 \pm 0.5$ & $16.5 \pm 1.2$ & $17.3 \pm 1.8$ & $15.8 \pm 0.3$ & $14.2 \pm 4.7$ & $15.3 \pm 1.1$ & $17.4 \pm 1.2$ \\
\hline $60-100$ & $14.2 \pm 0.6$ & $15.5 \pm 1.2$ & $14.4 \pm 0.4$ & $14.3 \pm 1.5$ & $14.7 \pm 4.9$ & $11.0 \pm 0.7$ & $15.5 \pm 1.8$ \\
\hline \multicolumn{8}{|l|}{ Bulk density, $\mathrm{g} \mathrm{cm}^{-3}$} \\
\hline $0-10$ & $0.61 \pm 0.08$ & $0.66 \pm 0.07$ & $0.50 \pm 0.08$ & $0.75 \pm 0.06$ & $0.79 \pm 0.09$ & $0.79 \pm 0.05$ & $0.91 \pm 0.10$ \\
\hline \multicolumn{8}{|c|}{ Organic $C$ content, $\mathrm{kg} \mathrm{C} \mathrm{m}-2$} \\
\hline $0-10$ & $3.01 \pm 0.48$ & $3.20 \pm 0.66$ & $3.06 \pm 0.63$ & $3.50 \pm 0.38$ & $3.93 \pm 0.41$ & $3.29 \pm 0.24$ & $1.90 \pm 0.38$ \\
\hline $10-20$ & $2.85 \pm 1.01$ & $2.07 \pm 0.36$ & $1.90 \pm 0.26$ & $2.30 \pm 0.09$ & $1.79 \pm 0.51$ & $2.45 \pm 0.15$ & $1.97 \pm 0.22$ \\
\hline $20-40$ & $4.35 \pm 0.95$ & $3.57 \pm 0.32$ & $3.89 \pm 0.32$ & $3.83 \pm 0.23$ & $3.35 \pm 0.45$ & $2.81 \pm 0.53$ & $3.24 \pm 0.59$ \\
\hline $40-60$ & $2.27 \pm 0.25$ & $2.81 \pm 0.74$ & $2.70 \pm 0.44$ & $1.91 \pm 0.12$ & $2.40 \pm 0.62$ & $2.50 \pm 0.25$ & $1.50 \pm 0.13$ \\
\hline $60-100$ & $2.94 \pm 0.40$ & $3.77 \pm 0.73$ & $3.87 \pm 1.06$ & $2.30 \pm 0.55$ & $2.16 \pm 0.27$ & $1.93 \pm 0.49$ & $2.59 \pm 0.46$ \\
\hline \multicolumn{8}{|l|}{ Root mass, $g^{-2}$} \\
\hline $0-10$ & $189 \pm 44 a$ & $208 \pm 97 a c$ & $466 \pm 91 c$ & $92 \pm 3 a b$ & $35 \pm 17 b$ & $49 \pm 36 b$ & $127 \pm 40 a b$ \\
\hline \multicolumn{8}{|c|}{ Soil respiration, $g \subset m^{-2} d^{-1}$} \\
\hline [Spring] & $12.1 \pm 0.24 a$ & $12.7 \pm 0.29 a$ & $12.5 \pm 0.40 \mathrm{a}$ & $7.23 \pm 0.12 b$ & $5.15 \pm 0.35 b$ & $5.04 \pm 0.05 b$ & NA \\
\hline [Summer] & $14.1 \pm 0.38 a$ & $15.0 \pm 0.27 a$ & $17.3 \pm 0.31 b$ & $7.70 \pm 0.13 b$ & $6.99 \pm 0.19 b$ & $5.04 \pm 0.09 b$ & NA \\
\hline [Fall] & $7.21 \pm 0.25 a$ & $10.1 \pm 0.44 a$ & $10.8 \pm 0.47 a$ & $5.62 \pm 0.18 a$ & $5.81 \pm 0.29 a$ & $4.30 \pm 0.14 a$ & NA \\
\hline \multicolumn{8}{|c|}{ Surface litter mass, $\mathrm{kg} \mathrm{m}^{-2}$} \\
\hline Organic horizon & $115 \pm 32 a$ & $133 \pm 53 a$ & $185 \pm 52 b$ & NA & $79 \pm 16 a$ & NA & NA \\
\hline \multicolumn{8}{|l|}{ Soil $p H$} \\
\hline $0-10$ & $4.87 \pm 0.05$ & $4.44 \pm 0.16$ & $4.14 \pm 0.26$ & $4.28 \pm 0.10$ & $4.61 \pm 0.08$ & $4.35 \pm 0.16$ & $4.47 \pm 0.06$ \\
\hline
\end{tabular}

${ }^{\dagger}$ Means $\pm S E$. Means followed by different letters are significantly different according to the Tukey HSD $(\alpha=0.05)$.

in bulk density is indicative of a large gain of SOM at the top of mineral soil $(0-10 \mathrm{~cm})$, as was observed, yet not statistically confirmed. Mean differences in bulk density of the $0-10 \mathrm{~cm}$ soils from the removal treatments were not significantly different $(p$ $<0.37$ ) from the CTL but showed a consistent pattern of greater soil bulk density, with an average relative increase of $27 \pm 2.1 \%$ by comparison to the CTL soil.

Observed changes in the mean carbon to nitrogen ratio (C:N) of the study soils were reflective of the treatment manipulations, yet no changes were found to be statistically significant $(p<$ 0.92). Reflective of the increased $N$ available from the needle litter relative to wood debris, the mean C:N content in the 0$10 \mathrm{~cm}$ DL soil declined by $22 \%$. Such an effect was limited to the surface of the DL soil, as minimal differences in C:N content were observed relative to CTL at lower depths. Despite the additional wood debris input, the DW soil C:N remained quite similar to the control at the soil surface. However, at $10-20 \mathrm{~cm}$ in the DW soil, a $24 \%$ increase in mean soil C:N content was observed. No further differences in soil C:N were notable between the DW and CTL at lower depths. The removal of surface litter (NL) led to no evident effects on soil C:N throughout the $0-100 \mathrm{~cm}$ profile. In contrast, soils without root activity (NR and NI treatments) had consistently lower mean C:N ratios than those found in CTL from $0-100 \mathrm{~cm}$, with slightly greater declines observed near the surface (Table 2). The C:N content of the $0-10 \mathrm{~cm}$ soil in the NOA was far more similar to the C:N content found at $10-20 \mathrm{~cm}$ in the CTL, reflecting the B-horizon origin of the added treatment soil.

Mean soil respiration rates were significantly lower for all of the detrital reduction treatments (NL, NR, NI) during spring and summer (Table 2, $p<0.02$ ), but not during fall. The decline in mean respiration was the greatest in the treatments with removed live roots, with an observed decline of 57 and $50 \%$ for the NR treatment in spring and summer, respectively. For the NI treatment, there was an observed decrease of $58 \%$ in spring 


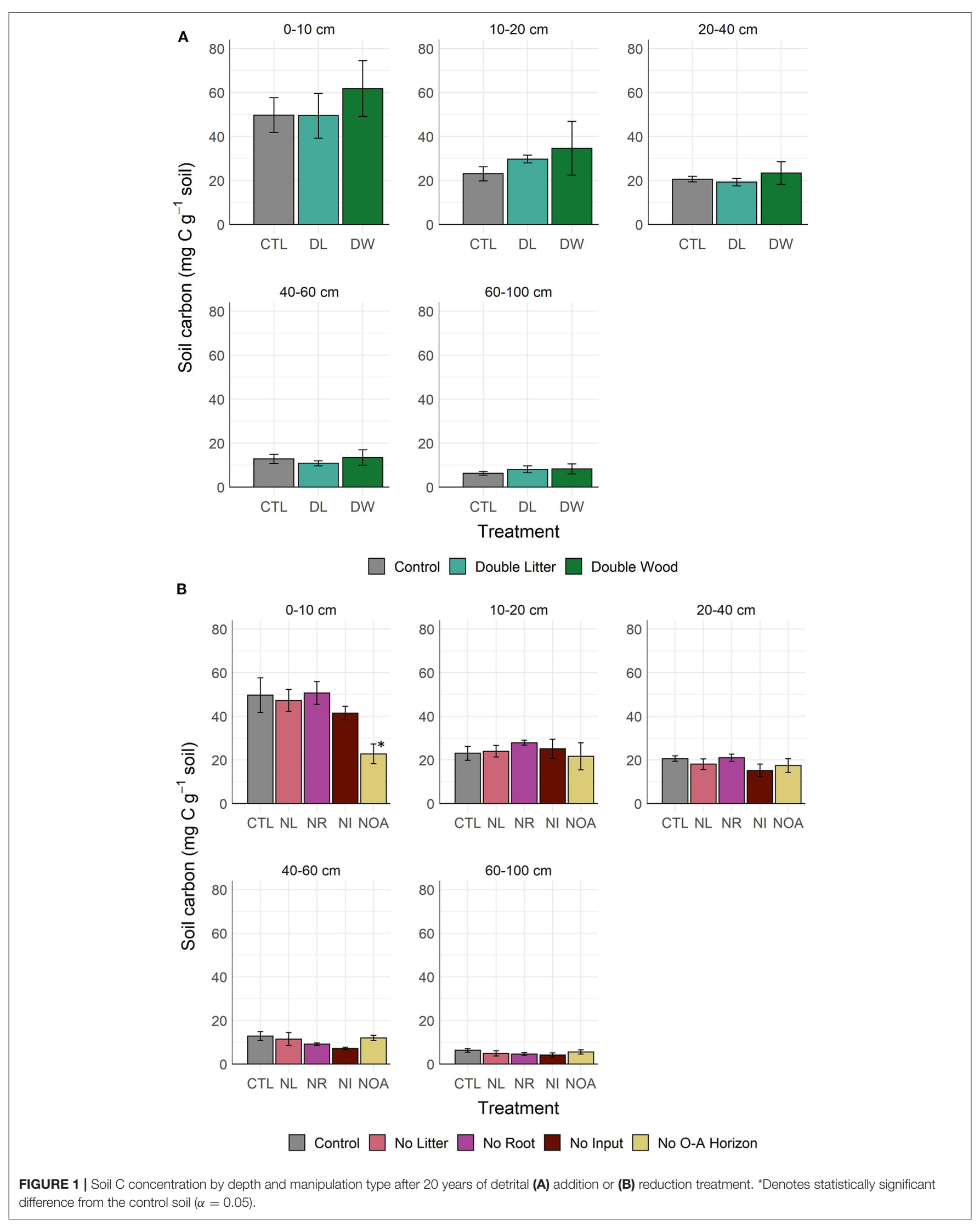




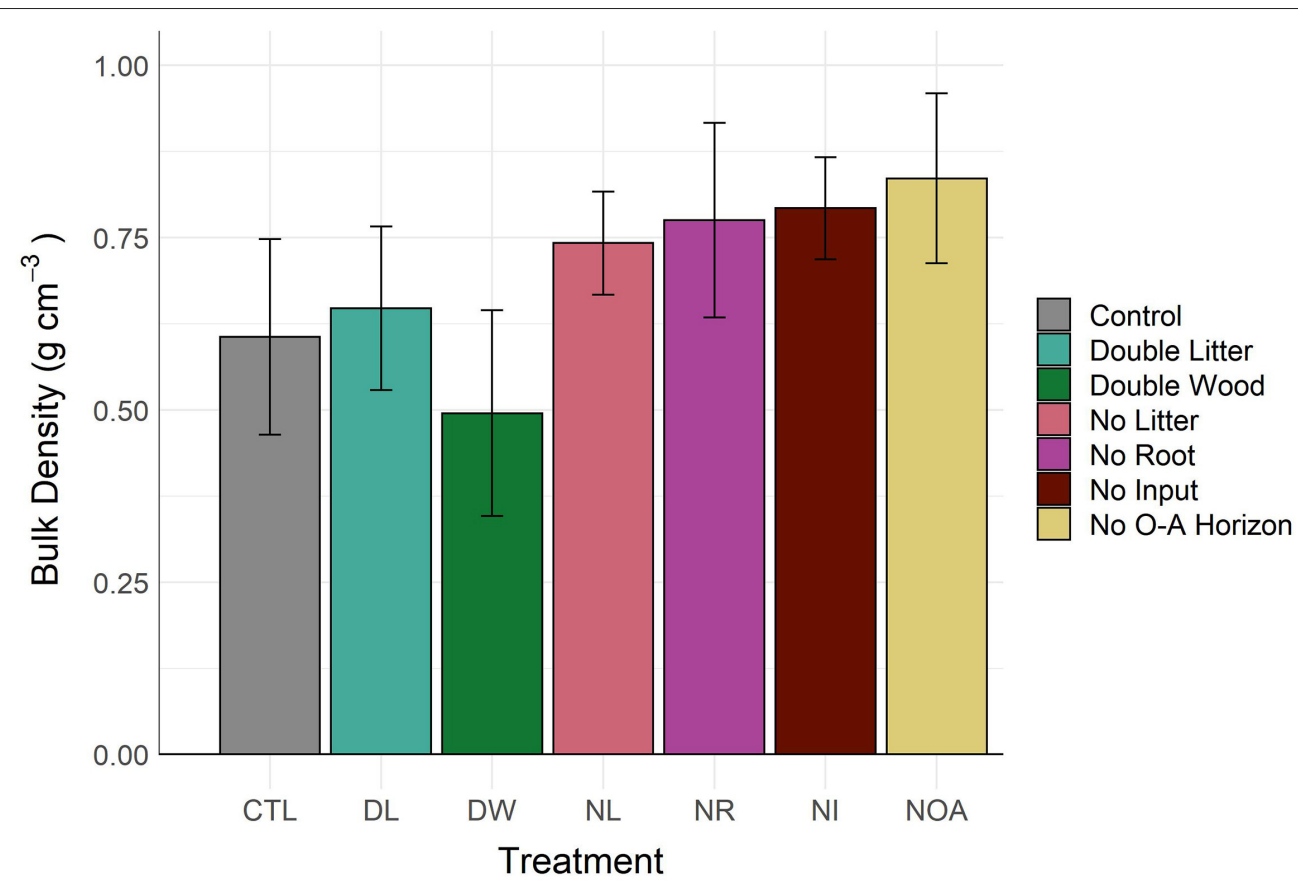

FIGURE 2 | About 0-10 cm soil bulk density by detrital treatment type after 20 years of manipulation. Differences in 0-10 cm soil bulk density between the control soil and the treatment soils are not statistically significant $(\alpha=0.05)$.

and $64 \%$ in summer. Mean respiration from the NL treatment soils declined by $40 \%$ in the spring and $45 \%$ in the summer. Increases in respiration from the detrital addition treatments were not significant in any season. We observed only a 5 and $6 \%$ increase in mean soil respiration from the DL treatment in spring and summer, respectively, and a $3 \%$ increase in spring and $23 \%$ increase in summer from the DW treatment. Increases in respiration were greater in the fall for DL and DW treatments, with a $40 \%$ increase in DL and $50 \%$ increase in DW; yet, these differences were also not significant.

The mass of surface litter (organic soil horizon) increased by $61 \%$ from the DW treatment relative to control (Figure 3, Table 2; $p<0.04$ ). Surface litter accumulation from the DL treatment was relatively minimal, with a non-significant mean difference of $+15 \%(p<0.92)$. The NR treatment was the only removal treatment to receive surface litter inputs. The removal of live roots led to an observed decline in surface litter by $31 \%$; yet, this change was not found to be statistically significant $(p<0.62)$. The NL and NI treatments resulted in the total loss of surface litter from the organic soil horizon.

Fine root mass in the $0-10 \mathrm{~cm}$ soil increased by $146 \%$ from the DW treatment ( $p<0.04$, Figure 4, Table 2), likely in response to a decline in bulk density and an increase in nutrients available from the additional surface litter decomposition. The DL treatment, for which we observed minimal effects on soil bulk density and surface litter mass, also had a non-significant effect on fine root mass $(p<0.99)$. Differences in fine roots between the CTL and the removal treatments were not statistically significant, yet, large mean differences were observed across all removal treatments. The NR and NI treatment applications were successful in reducing root activity in the soils, as we found a $>74 \%$ reduction in fine root mass across soils in both treatments $(p<0.01)$. The NL treatment may have also affected plant roots in the mineral soil, leading to an observed decline of $51 \%$ in fine root mass relative to CTL $(p<0.09)$.

Treatment effects on soil C stocks were not directly proportionate with the effects on soil $\mathrm{C}$ concentrations due to associated changes in soil bulk density (Figure 5, Table 2). To properly account for the effects of changing bulk density, the soil $\mathrm{C}$ content was calculated using equivalent soil mass. Differences between stocks were not found statistically significant in comparisons between the CTL and the separate manipulation treatments $(p<0.99)$, yet, some substantial changes in mean C stocks were observed near the soil surface. Following the 20year study period, the observed $0-10 \mathrm{~cm}$ DL treatment soil C stocks changed by $+13 \%$ relative to CTL, while the $0-10 \mathrm{~cm} \mathrm{DW}$ treatment soil $\mathrm{C}$ stocks changed by $+24 \%$. Effects on surface mineral $(0-10 \mathrm{~cm})$ soil $\mathrm{C}$ stocks from the NL and NR treatments were small, with an observed difference of $<5 \%$ relative to the CTL. The $0-10 \mathrm{~cm}$ NI treatment soil C stocks declined by $17 \%$, while the $0-10 \mathrm{~cm}$ NOA treatment soil C stocks declined by $37 \%$. Soil C stocks at a depth $>10 \mathrm{~cm}$ are reported with the assumption of equal bulk density across treatment types as no significant change in bulk density was found at $10-15 \mathrm{~cm}$ soil depth across all the treatment plots.

\section{DISCUSSION}

The findings of this study provide a multi-decadal, field-based exploration of how changes in above- and belowground detrital 


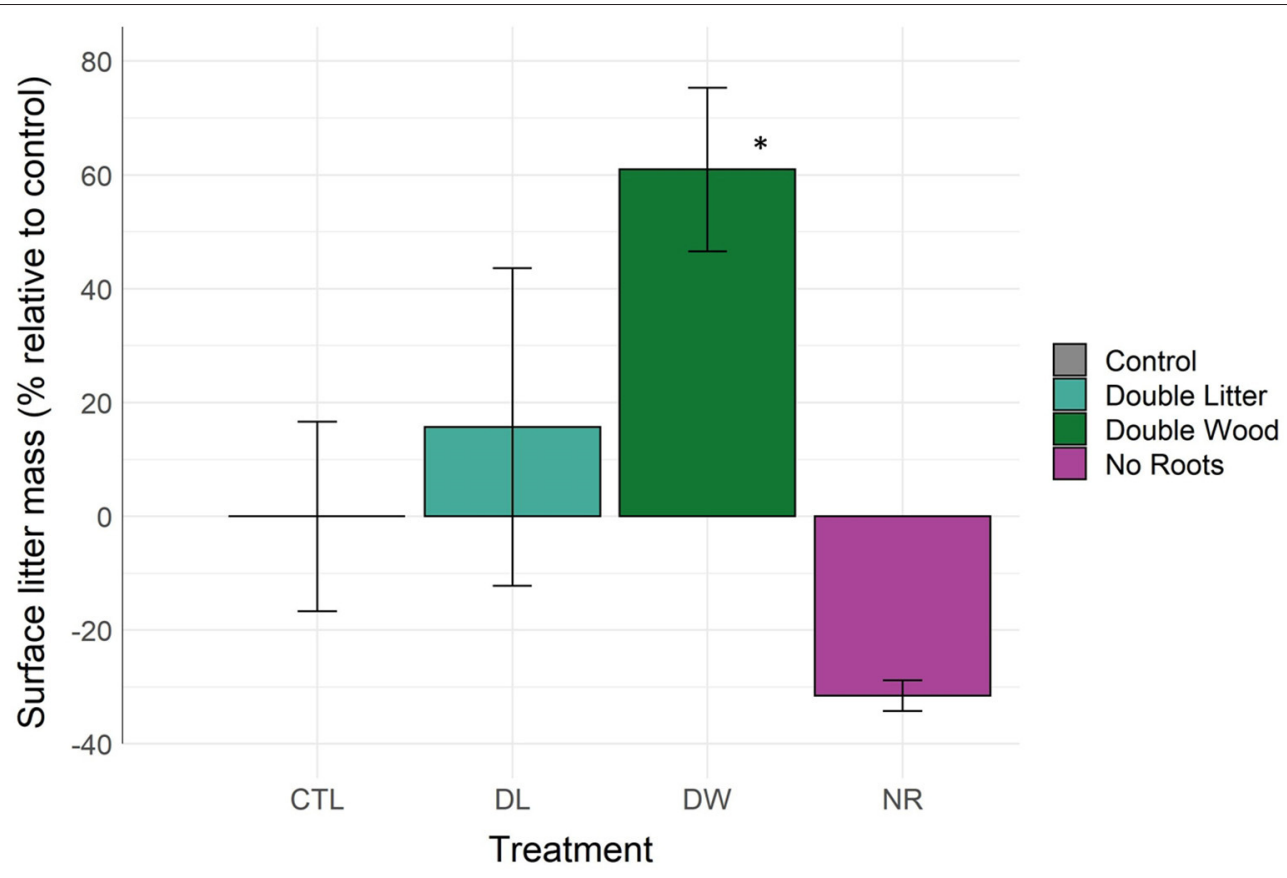

FIGURE 3 | Litter mass above the mineral soil surface by detrital treatment type after 20 years of manipulation. *Denotes statistically significant difference from the control soil $(\alpha=0.05)$.

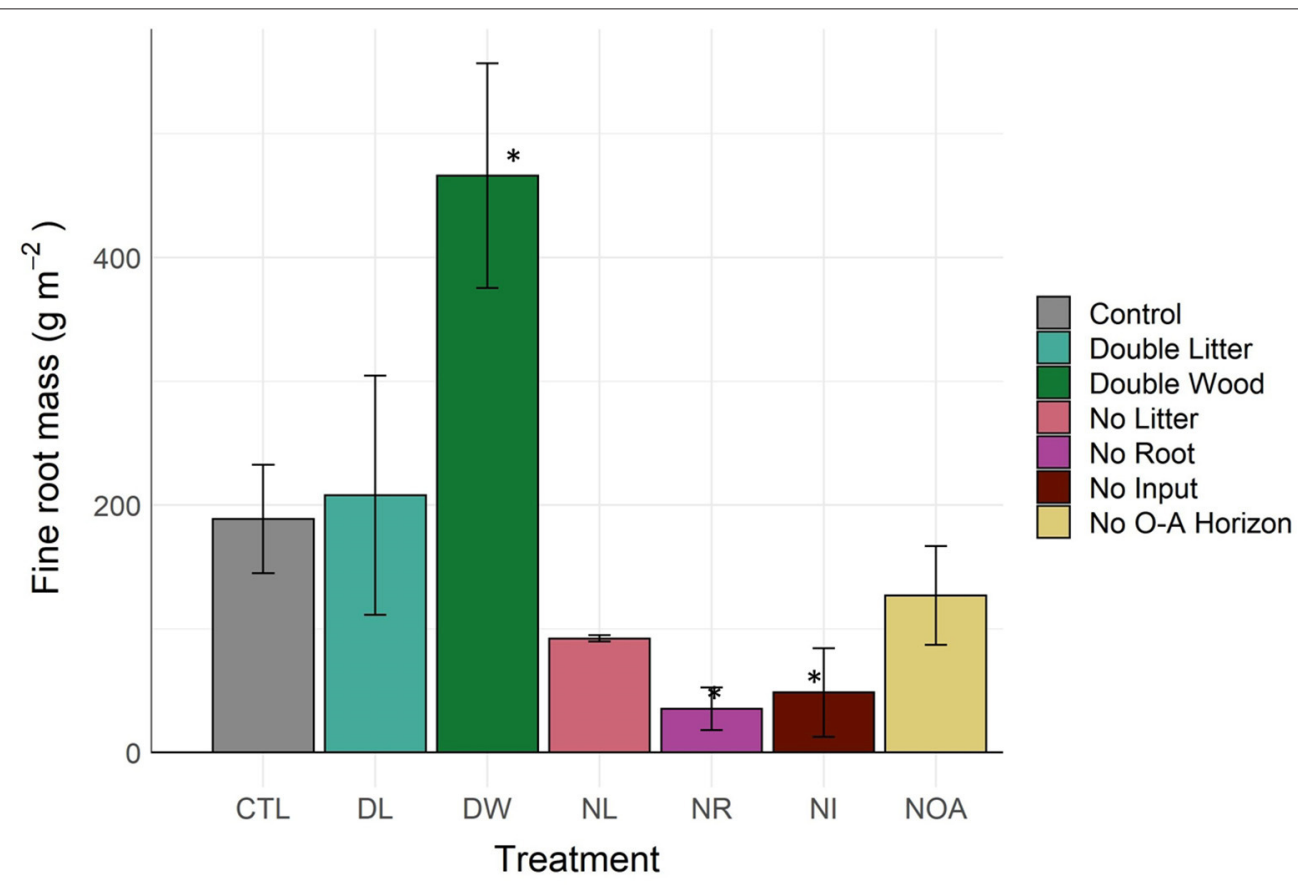

FIGURE 4 | Fine $(<2 \mathrm{~mm})$ root mass of 0-10 cm soil by detrital treatment type after 20 years of manipulation. *Denotes statistically significant difference from the control soil $(\alpha=0.05)$.

inputs may alter soil C stocks in the temperate conifer forests of the Pacific Northwest United States. These wet temperate forests are highly productive and $\mathrm{C}$ rich, containing more $\mathrm{C}$ in aboveground biomass and soil than nearly any other forest system on earth (Smithwick et al., 2002). After 20 years of sustained detrital addition and removal treatments, we were 


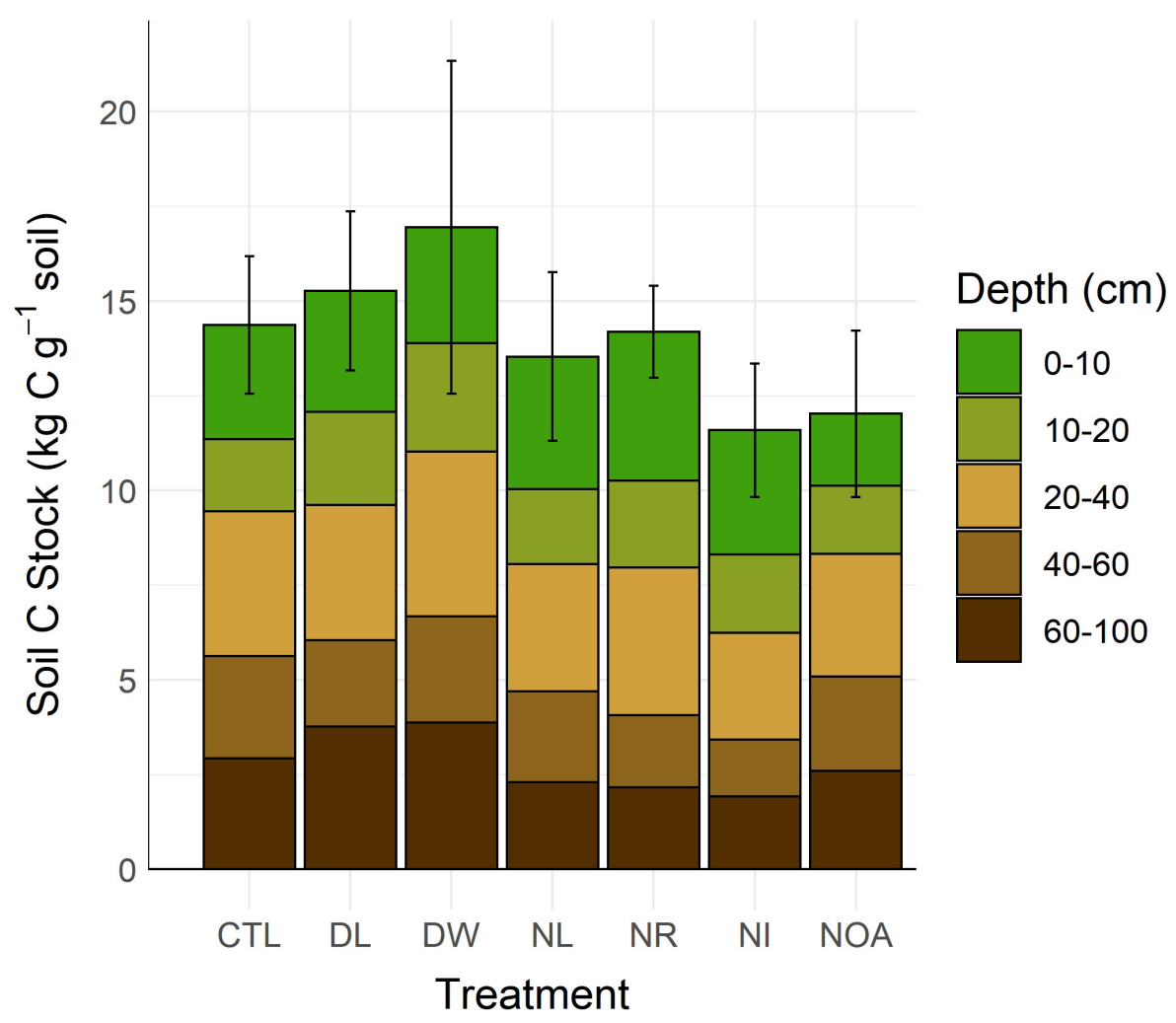

FIGURE 5 | Soil C stocks by detrital treatment type after 20 years of manipulation (CTL, Control; DL, Double litter; DW, Double wood; NL, No Litter; NR, No roots; NI, No inputs; NOA, No O-A horizons). Differences in soil C stocks were not statistically significant $(\alpha=0.05)$.

surprised to find few significant changes in soil $\mathrm{C}$ and related soil properties. Field experiments remain as our best, direct, in situ avenue toward improving our mechanistic knowledge of soil C stabilization dynamics, as the complexities of biogeochemical interactions in natural systems are not well-replicable in a laboratory environment (Malhotra et al., 2019). While this complexity presents challenges in isolating treatment effects and determining statistical differences, a broader assessment of the common trends across separate, yet related analyses provides valuable insight into the potential effects of shifting organic matter inputs to soils.

In the analyses of the detrital treatment effects on soil $\mathrm{C}$ concentrations performed in this study, the DL treatment was consistently similar to the untreated CTL soil. This was an unexpected result, as it appears very little of the additional surface litter $\mathrm{C}$ was transferred to the mineral soil. The lack of a decline in bulk density further corroborates this finding. The strong evidence that the DL treatment had minimal effect on soil $\mathrm{C}$ invites the question: where did the additional litter $\mathrm{C}$ go over the 20-year study period? Addressing the possibility that the additional litter may have built upon the soil surface, we found that gains in surface litter mass of the organic horizon on the DL plots were also not significantly different from CTL, though confidence intervals from the statistical analysis in this study allow that litter stocks may have increased slightly. However, we certainly did not observe an increase in standing surface litter mass of the magnitude necessary to account for any significant portion of the additional litter inputs. Substantial transfer of litter material off-plot due to erosion and wind is highly unlikely, as the terrain of the study area is close to flat, the winds are generally calm, and the additional litter quickly nestles in the forest floor, well-protected by the dense understory vegetation. Thus, it appears most likely that much of the litter material was decomposed by the microbial community, and the associated $\mathrm{C}$ was subsequently lost through respiration or leaching of dissolved organic carbon (DOC). A recent study of DOC production and transport from the HJAF DIRT plots estimated that the DOC losses from the DL soils were generally equivalent to those from the CTL soil, and thus unlikely to be responsible for an increased portion of the litter $\mathrm{C}$ loss (Evans et al., 2020). Further, losses of $C$ to leaching consistently account for only a small percentage of $\mathrm{C}$ losses relative to those from respiration in the HJAF DIRT plots (Lajtha et al., 2005). Thus, the elevated summer and fall soil respiration rates observed from the DL soils appear to be the greatest observed driver for the loss of the additional litter $\mathrm{C}$ input.

Increasing aboveground litter in forest systems has rarely led to an increase in soil $\mathrm{C}$ content, strongly suggesting that the processes for transforming surface litter to SOM are more complex than a simple positive linear relationship between litterfall quantity and soil $\mathrm{C}$ accumulation. Similar DIRT experiments at the Bousson and Harvard Experimental 
Forests, both located in deciduous hardwood forests in the northeastern United States, found no change in soil C after doubling surface litter inputs over a 20-year period (Bowden et al., 2014; Lajtha et al., 2014a). A recent study of detrital additions in the tropical forest of Panama also reported no significant change in soil $\mathrm{C}$ after 13 years of doubling aboveground litter inputs (Sayer et al., 2019). Results from the DIRT experiment performed in this study provide further scope for the pervasiveness of these trends. The observed absence of soil $\mathrm{C}$ change from the litter additions at HJAF suggests that highly productive forests with dense ecosystem $\mathrm{C}$ stocks are also not likely to gain soil $\mathrm{C}$ from increases in litterfall. Soils at the HJAF are unique from the other DIRT network sites, with their andic soil properties (reactive clay minerals) offering substantial reactive capacity for mineral stabilization of organic matter (Sollins et al., 2006; Matus et al., 2014). We expected these unique site properties at the HJAF to provide greater opportunity for the detrital litter additions to increase soil C. Yet, the results of this study, taken along with those from other previous studies, suggest that additional aboveground litter inputs are not likely to alter soil C concentrations in most forest soils and that the role of forest vegetation type, soil mineralogy, and climate require further study and attention as moderators of the relationship between litter inputs and soil C sequestration.

The double wood (DW) treatment, for which the experimental plots received annual additions of wood chips in an equal proportion to litterfall, led to a starkly different response in soil $\mathrm{C}$-related properties relative to the DL treatment. Among the two additional treatments, the DW clearly provided a greater likelihood for increasing soil C over the 20 -year study. The DW soils were found to have substantial increases in mean organic horizon mass, mean soil $\mathrm{C}$ concentrations and stocks, and mean annual respiration rates relative to the CTL. At this time, when viewed as a combined set of treatment effects, a consistent trend is observed, which suggests that the woody debris is promoting soil $\mathrm{C}$ accumulation both above- and belowground. The slow decomposition rate of woody debris is likely the mechanism for such C gains, as slower rates of decomposition provide greater time for the accumulation and distribution of organic matter in the soil profile. Differences in decomposition rates between wood and needle litter have long been recognized (McClaugherty et al., 1982; Melillo et al., 1982) and may be attributed primarily to the low quality (high C:N) of the wood debris relative to the more nutrient-rich needle litter (Bradford et al., 2016). Other studies have also shown that factors such as the presence of complex molecular structures (e.g., lignin) may also slow decomposition (Talbot et al., 2012; Rahman et al., 2013). Combining this information together with the observed results, we see strong evidence that a sustained increase in woody debris has greater potential than additions of needle litter to increase soil C stocks over short decadal timescales. However, based on the associated decline in DW soil bulk density, we suspect these apparent increases in soil $\mathrm{C}$ stocks are derived directly from increases in free particulate, undecomposed woody debris rather than increases in mineral-stabilized C pools. How these gains in particulate SOM will contribute to the amount of stabilized SOC in the mineral soil remains unknown and an important avenue for future research.

The observed differences in litter decomposition between the DL and DW treatments offer insight into the validity of current hypotheses pertaining to the stabilization of soil C. Additional organic inputs to soils have been recognized to have the potential to cause priming effects (Kuzyakov, 2010), where an increase in microbial activity following substrate addition results in a net loss of SOC. Priming effects are more likely from highquality (low C:N) material, such as the needle litter in this study, which provides a greater abundance of limiting nutrients along with necessary $\mathrm{C}$ energy source to stimulate microbial activity (Wang et al., 2015). As priming effects have largely been studied in laboratory experiments, the magnitude of the influence that these phenomena may have on soil C stocks in natural systems is less well-known (Wutzler and Reichstein, 2013; Cardinael et al., 2015). Priming effects may explain the lack of an observed increase in soil $\mathrm{C}$ from the DL treatment by serving to offset any new gains in soil $\mathrm{C}$ which may have occurred in response to the additional litter. To provide further perspective on the role of priming effects on soils in natural forest environments, future analysis of age differences in SOC between treatment soils may provide the opportunity to further understand the interplay between litter quality, priming, and soil $\mathrm{C}$ accumulation.

We initially hypothesized that a greater increase in mineral soil $\mathrm{C}$ would result from the addition of higher-quality needle litter, as opposed to the addition of lower-quality wood debris. The hypothesis proposed in this study was based on the expectation that greater amounts of the high-quality substrate would lead to greater rates of microbial processing, improved carbon use efficiency, and subsequently more microbial products in the soil (Bradford et al., 2013; Winsome et al., 2017; Córdova et al., 2018). Previous studies have widely shown that SOC stabilized by organo-mineral interactions often resembles microbially processed material in structure and molecular composition, rather than the raw molecular components directly derived from the degradation of plant material (Sollins et al., 2009; Mambelli et al., 2011). These findings have led to hypotheses postulating that the microbial processing of organic inputs facilitates subsequent SOC complexation with mineral surfaces (Cotrufo et al., 2013). The lack of an increase in DL soil $\mathrm{C}$ following 20 years of elevated microbial decomposition rates suggests additional controls may regulate the potential for mineral soil $\mathrm{C}$ gains from enhanced microbial processing. Alternatively, the timescale required for the SOC accumulation may exceed the period of the current study, as 20 years is a relatively short time for forest soil development.

Broadly, results from the removal treatments suggest that mineral soil $\mathrm{C}$ concentrations in these temperate forest soils are quite resistant to decline over two decades of reductions in aboveor belowground detrital organic matter inputs. Surprisingly, soils with no detrital contributions from surface litter (NL) or live roots (NR) maintained soil $\mathrm{C}$ concentrations in a near-identical manner to the otherwise natural soils (CTL). A lack of soil C loss from the NL treatment without an observed increase in fine root growth may suggest that forest soil $\mathrm{C}$ concentrations are supported largely by root activity. Further, the observed decline 
in organic horizon mass above the NR treatment suggests that in the absence of root activity, the surface litter may be more actively decomposed to sustain microbial activity and support soil C concentrations. As expected, the greatest potential for loss of soil C occurred when both above- and belowground detrital input sources were reduced (NI). The observed rates of respiration in the NI soils, along with the lack of a severe decline in soil $\mathrm{C}$, shows that the soils continued to receive some amount of fresh organic inputs through the surface litter screens and possibly a few remaining live roots. Potential explanations for the persistence of soil $\mathrm{C}$ concentrations in the NI soils include the following: (1) a substantial portion of the mineral soil $\mathrm{C}$ is stabilized or otherwise well-protected and unavailable for microbial decomposition (Castellano et al., 2015); (2) microbial activity and community composition strongly regulate changes in soil C concentration (Georgiou et al., 2017; Liang et al., 2017); (3) relatively small amounts of detrital organic matter inputs to the soil may be sufficient over the course of the study period to prevent greater losses of soil C. Further study of the mineral matrix capacity for organo-mineral complexations, as well as detrital influences on the microbial community and processing pathways, will be necessary to better elucidate the relative level of contribution of these biogeochemical controls toward soil C stabilization.

Losses of soil $\mathrm{C}$ from the treatment reductions in above- and belowground detrital inputs at the HJAF were less substantial than soil C losses observed after 20 years at similar DIRT sites in other forest environments (Bowden et al., 2014; Lajtha et al., 2014a,b). However, declining soil C trends from the NR and NI treatments were similar. The findings of this study from HJAF DIRT expand the scope of these trends and provide further evidence that a reduction in live root activity leads to minimal effects on forest soil $\mathrm{C}$, which are largely irrespective of differences in soils, climate, and vegetation, over short decadal timescales. In contrast, the NL treatment at HJAF had far less effect on soil $\mathrm{C}$ concentration than those observed across the other DIRT sites. A greater abundance of roots in the surface soils at the HJAF may explain this disparity.

The NOA treatment accumulated a minimal amount of soil carbon in the upper $0-20 \mathrm{~cm}$ of mineral soil, despite 20 years of direct litter inputs to the soil surface and a large return of belowground root activity. Similar to the DL treatment, this finding shows remarkable resistance to increases in soil C from detrital additions. This lack of increase in soil $\mathrm{C}$ suggests

\section{REFERENCES}

Amelung, W., Brodowski, S., Sandhage-Hofmann, A., and Bol, R. (2008). Combining biomarker with stable isotope analyses for assessing the transformation and turnover of soil organic matter. Adv. Agron. 100, 155-250. doi: 10.1016/S0065-2113(08)00606-8

Angst, G., Mueller, K. E., Eissenstat, D. M., Trumbore, S., Freeman, K. H., Hobbie, S. E., et al. (2019). Soil organic carbon stability in forests: distinct effects of tree species identity and traits. Glob. Chang. Biol. 25, 1529-1546. doi: $10.1111 /$ gcb. 14548

Bailey, V. L., Pries, C. H., and Lajtha, K. (2019). What do we know about soil carbon destabilization? Environ. Res. Lett. 14, 1-15. doi: 10.1088/1748-9326/ab2c11 that the timescale for soil $\mathrm{C}$ accumulation and development is far greater than the 20-year period of this study, which was unexpected given the high reactivity of the andic B-horizon fill material.

The observed effects on soil $\mathrm{C}$ from the detrital manipulation treatments support further investigation of the mechanisms which connect litter quantity and quality to soil C stocks. The stark differences in soil response to additions of needle litter vs. that to additions of wood debris suggest that quality may be the foremost determining factor governing how changes in temperate forest detrital input quantity influence soil $\mathrm{C}$ accumulation. Further, it is apparent that belowground detrital inputs have a greater supporting role for soil $\mathrm{C}$ than aboveground litter inputs, suggesting that long-term disturbances or management actions which reduce root activity may deplete soil C stocks. Moving forward and building from this preliminary 20-year assessment of soil C change in the HJAF DIRT experiment, we expect further studies to investigate changes in specific mineral soil $\mathrm{C}$ pools, $\mathrm{N}$ cycling, and microbial decomposition dynamics to further refine our knowledge of the linkages between forest soil $\mathrm{C}$ stocks and detrital input quantity and quality.

\section{DATA AVAILABILITY STATEMENT}

The datasets generated for this study are available on request to the corresponding author. Open-access to soil data from across the DIRT Network is available through the SOils DAta Harmonization (SoDaH) database, online at https://cosima. nceas.ucsb.edu/lter-som/.

\section{AUTHOR CONTRIBUTIONS}

$\mathrm{DP}, \mathrm{RB}, \mathrm{KN}$, and KL planned the research. DP, HP-C, KK, and LE conducted the field and laboratory research. DP, HP-C, and $\mathrm{KL}$ analyzed results. DP wrote the paper with KL. All authors contributed to the article and approved the submitted version.

\section{FUNDING}

Support was provided by the National Science Foundation Grants DEB-1257032 to KL and DEB-1440409 to the H.J. Andrews Long-Term Ecological Research Program. B., et al. (2014). Estimating the organic carbon stabilisation capacity and saturation deficit of soils: a New Zealand case study. Biogeochemistry 120, 71-87. doi: 10.1007/s10533-014-9982-1

Bowden, R. D., Deem, L., Plante, A. F., Peltre, C., Nadelhoffer, K., and Lajtha, K. (2014). Litter input controls on soil carbon in a temperate deciduous forest. Soil Sci. Soc. Am. J. 78, S66-S75. doi: 10.2136/sssaj2013.09.0413nafsc

Bradford, M. A., Berg, B., Maynard, D. S., Wieder, W. R., and Wood, S. A. (2016). Understanding the dominant controls on litter decomposition. J. Ecol. 104, 229-238. doi: 10.1111/1365-2745.12507

Bradford, M. A., Keiser, A. D., Davies, C. A., Mersmann, C. A., and Strickland, M. S. (2013). Empirical evidence that soil carbon formation from plant 
inputs is positively related to microbial growth. Biogeochemistry 113, 271-281. doi: 10.1007/s10533-012-9822-0

Campos, X., Germino, M. J., and de Graaff, M. A. (2017). Enhanced precipitation promotes decomposition and soil $\mathrm{C}$ stabilization in semiarid ecosystems, but seasonal timing of wetting matters. Plant Soil 416, 427-436. doi: 10.1007/s11104-017-3221-1

Cardinael, R., Eglin, T., Guenet, B., Neill, C., Houot, S., and Chenu, C. (2015). Is priming effect a significant process for long-term SOC dynamics? Analysis of a 52-years old experiment. Biogeochemistry 123, 203-219. doi: 10.1007/s10533-014-0063-2

Castellano, M. J., Mueller, K. E., Olk, D. C., Sawyer, J. E., and Six, J. (2015). Integrating plant litter quality, soil organic matter stabilization, and the carbon saturation concept. Glob. Chang. Biol. 21, 3200-3209. doi: 10.1111/gcb. 12982

Chen, H., Li, D., Feng, W., Niu, S., Plante, A., Luo, Y., et al. (2018). Different responses of soil organic carbon fractions to additions of nitrogen. Eur. J. Soil Sci. 69, 1098-1104. doi: 10.1111/ejss.12716

Chen, Z. J., Geng, S. C., Zhang, J. H., Setälä, H., Gu, Y., Wang, F., et al. (2017). Addition of nitrogen enhances stability of soil organic matter in a temperate forest. Eur. J. Soil Sci. 68, 189-199. doi: 10.1111/ejss.12404

Chung, H., Ngo, K. J., Plante, A., and Six, J. (2010). Evidence for carbon saturation in a highly structured and organic-matter-rich soil. Soil Sci. Soc. Am. J. 74, 130-138. doi: 10.2136/sssaj2009.0097

Córdova, S. C., Olk, D. C., Dietzel, R. N., Mueller, K. E., Archontouilis, S. V., and Castellano, M. J. (2018). Plant litter quality affects the accumulation rate, composition, and stability of mineral-associated soil organic matter. Soil Biol. Biochem. 125, 115-124. doi: 10.1016/j.soilbio.2018. 07.010

Cotrufo, M. F., Wallenstein, M. D., Boot, C. M., Denef, K., and Paul, E. (2013). The microbial efficiency-matrix stabilization (MEMS) framework integrates plant litter decomposition with soil organic matter stabilization: do labile plant inputs form stable soil organic matter? Glob. Chang. Biol. 19, 988-995. doi: $10.1111 /$ gcb.12113

Crow, S. E., Lajtha, K., Filley, T. R., Swanston, C. W., Bowden, R. D., and Caldwell, B. A. (2009). Sources of plant-derived carbon and stability of organic matter in soil: implications for global change. Glob. Chang. Biol. 15, 2003-2019. doi: 10.1111/j.1365-2486.2009.01850.x

Davidson, E. A., and Janssens, I. A. (2006). Temperature sensitivity of soil carbon decomposition and feedbacks to climate change. Nature 440, 165-173. doi: 10.1038 /nature04514

Davidson, E. A., Trumbore, S. E., and Amundson, R. (2000). Biogeochemistry: soil warming and organic carbon content. Nature 408, 789-790. doi: $10.1038 / 35048672$

De Graaff, M. A., Jastrow, J. D., Gillette, S., Johns, A., and Wullschleger, S. D. (2014). Differential priming of soil carbon driven by soil depth and root impacts on carbon availability. Soil Biol. Biochem. 69, 147-156. doi: 10.1016/j.soilbio.2013.10.047

Evans, L. R., Pierson, D., and Lajtha, K. (2020). Dissolved organic carbon production and flux under long-term litter manipulations in a Pacific Northwest old-growth forest. Biogeochemistry 149, 75-86. doi: 10.1007/s10533-020-00667-6

Fekete, I., Kotroczó, Z., Varga, C., Nagy, P. T., Várbíró, G., Bowden, R. D., et al. (2014). Alterations in forest detritus inputs influence soil carbon concentration and soil respiration in a central-european deciduous forest. Soil Biol. Biochem. 74, 106-114. doi: 10.1016/j.soilbio.2014.03.006

Finley, B. K., Dijkstra, P., Rasmussen, C., Schwartz, E., Mau, R. L., Liu, X. J. A., et al. (2018). Soil mineral assemblage and substrate quality effects on microbial priming. Geoderma 322, 38-47. doi: 10.1016/j.geoderma.2018.01.039

Fontaine, S., Bardoux, G., Abbadie, L., and Mariotti, A. (2004). Carbon input to soil may decrease soil carbon content. Ecol. Lett. 7, 314-320. doi: 10.1111/j.1461-0248.2004.00579.x

Georgiou, K., Abramoff, R. Z., Harte, J., Riley, W. J., and Torn, M. S. (2017). Microbial community-level regulation explains soil carbon responses to long-term litter manipulations. Nat. Commun. 8, 1-10. doi: 10.1038/s41467-017-01116-z

Georgiou, K., Koven, C. D., Riley, W. J., and Torn, M. S. (2015). Toward improved model structures for analyzing priming: potential pitfalls of using bulk turnover time. Glob. Chang. Biol. 21, 4298-4302. doi: 10.1111/gcb.13039
Gleixner, G. (2013). Soil organic matter dynamics: a biological perspective derived from the use of compound-specific isotopes studies. Ecol. Res. 28, 683-695. doi: 10.1007/s11284-012-1022-9

Gottschalk, P., Smith, J. U., Wattenbach, M., Bellarby, J., Stehfest, E., Arnell, N., et al. (2012). How will organic carbon stocks in mineral soils evolve under future climate? Global projections using RothC for a range of climate change scenarios. Biogeosci. Discuss. 9, 411-451. doi: 10.5194/bgd-9-411-2012

Griscom, B. W., Adams, J., Ellis, P. W., Houghton, R. A., Lomax, G., Miteva, D. A., et al. (2017). Natural climate solutions. Proc. Natl. Acad. Sci. U.S.A. 114, 11645-11650. doi: 10.1073/pnas.1710465114

Harden, J. W., Hugelius, G., Ahlstr, A., Lawrence, C. R., Loisel, J., Bond-lamberty, J. C. B., et al. (2018). Networking our science to characterize the state, vulnerabilities, and management opportunities of soil organic matter. Glob. Chang. Biol. 705-718. doi: 10.1111/gcb.13896

Horner, J. D., Cates, R. G., and Gosz, J. R. (1987). Tannin, nitrogen, and cell wall composition of green vs. senescent Douglas-fir foliage. Oecologia 72, 515-519. doi: $10.1007 /$ BF00378976

Jackson, O., Quilliam, R. S., Stott, A., Grant, H., and Subke, J. A. (2019). Rhizosphere carbon supply accelerates soil organic matter decomposition in the presence of fresh organic substrates. Plant Soil 440, 473-490. doi: 10.1007/s11104-019-04072-3

Janzen, H. H. (2004). Carbon cycling in earth systems - a soil science perspective. Agric. Ecosyst. Environ. 104, 399-417. doi: 10.1016/j.agee.2004.01.040

Kallenbach, C. M., Frey, S. D., and Grandy, A. S. (2016). Direct evidence for microbial-derived soil organic matter formation and its ecophysiological controls. Nat. Commun. 7, 1-10. doi: 10.1038/ncomms13630

Kätterer, T., Bolinder, M. A., Andrén, O., Kirchmann, H., and Menichetti, L. (2011). Roots contribute more to refractory soil organic matter than aboveground crop residues, as revealed by a long-term field experiment. Agric. Ecosyst. Environ. 141, 184-192. doi: 10.1016/j.agee.2011.02.029

Keiluweit, M., Bougoure, J. J., Nico, P. S., Pett-Ridge, J., Weber, P. K., and Kleber, M. (2015). Mineral protection of soil carbon counteracted by root exudates. Nat. Clim. Chang. 5, 588-595. doi: 10.1038/nclimate2580

Kirilenko, A. P., and Sedjo, R. A. (2007). Climate change impacts on forestry. Proc. Natl. Acad. Sci. U.S.A. 104, 19697-19702. doi: 10.1073/pnas.0701424104

Kuzyakov, Y. (2010). Priming effects: interactions between living and dead organic matter. Soil Biol. Biochem. 42, 1363-1371. doi: 10.1016/j.soilbio.2010.04.003

Kuzyakov, Y., and Blagodatskaya, E. (2015). Microbial hotspots and hot moments in soil: concept \& review. Soil Biol. Biochem. 83, 184-199. doi: 10.1016/j.soilbio.2015.01.025

Lajtha, K., Bowden, R. D., Crow, S., Fekete, I., Kotroczó, Z., Plante, A., et al. (2018). The detrital input and removal treatment (DIRT) network: insights into soil carbon stabilization. Sci. Total Environ. 640-641, 1112-1120. doi: 10.1016/j.scitotenv.2018.05.388

Lajtha, K., Bowden, R. D., and Nadelhoffer, K. (2014a). Litter and root manipulations provide insights into soil organic matter dynamics and stability. Soil Sci. Soc. Am. J. 78, S261-S269. doi: 10.2136/sssaj2013.08.0370nafsc

Lajtha, K., Crow, S. E., Yano, Y., Kaushal, S. S., Sulzman, E., Sollins, P., and Spears, J. D. H. (2005). Detrital controls on soil solution $\mathrm{N}$ and dissolved organic matter in soils: a field experiment. Biogeochemistry 76, 261-281. doi: 10.1007/s10533-005-5071-9

Lajtha, K., Townsend, K. L., Kramer, M. G., Swanston, C., Bowden, R. D., and Nadelhoffer, K. (2014b). Changes to particulate versus mineral-associated soil carbon after 50 years of litter manipulation in forest and prairie experimental ecosystems. Biogeochemistry 119, 341-360. doi: 10.1007/s10533-0149970-5

Liang, C., Schimel, J. P., and Jastrow, J. D. (2017). The importance of anabolism in microbial control over soil carbon storage. Nat. Microbiol. 2, 1-6. doi: 10.1038/nmicrobiol.2017.105

Liski, J., Perruchoud, D., and Karjalainen, T. (2002). Increasing carbon stocks in the forest soils of western Europe. For. Ecol. Manage. 169, 159-175. doi: 10.1016/S0378-1127(02)00306-7

Malhotra, A., Todd-Brown, K., Nave, L. E., Batjes, N. H., Holmquist, J. R., Hoyt, A. M., et al. (2019). The landscape of soil carbon data: emerging questions, synergies and databases. Prog. Phys. Geogr. 43, 707-719. doi: 10.1177/0309133319873309

Mambelli, S., Bird, J. A., Gleixner, G., Dawson, T. E., and Torn, M. S. (2011) Relative contribution of foliar and fine root pine litter to the molecular 
composition of soil organic matter after in situ degradation. Org. Geochem. 42, 1099-1108. doi: 10.1016/j.orggeochem.2011.06.008

Matus, F., Rumpel, C., Neculman, R., Panichini, M., and Mora, M. L. (2014). Soil carbon storage and stabilisation in andic soils: a review. Catena 120, 102-110. doi: 10.1016/j.catena.2014.04.008

Mayzelle, M. M., Krusor, M. L., Lajtha, K., Bowden, R. D., and Six, J. (2014). Effects of detrital inputs and roots on carbon saturation deficit of a temperate forest soil. Soil Sci. Soc. Am. J. 78, S76-S83. doi: 10.2136/sssaj2013.09.0415nafsc

McClaugherty, C. A., Aber, J. D., and Melillo, J. M. (1982). The role of fine roots in the organic matter and nitrogen budgets of two forested ecosystems. Ecology 63, 1481-1490. doi: 10.2307/1938874

McKinley, D. C., Ryan, M. G., Birdsey, R. A., Giardina, C. P., Harmon, M. E., Heath, L. S., et al. (2011). A synthesis of current knowledge on forests and carbon storage in the United States. Ecol. Appl. 21, 1902-1924. doi: 10.1890/10-0697.1

Means, J. E., MacMillan, P. C., and Cromack, K. Jr. (1992). Biomass and nutrient content of Douglas-fir logs and other detrital pools in an old-growth forest, Oregon, USA. Can. J. Forest Res. 22, 1536-1546. doi: 10.1139/x92-204

Melillo, J. M., Aber, J. D., and Muratore, J. F. (1982). Nitrogen and lignin control of hardwood leaf litter decomposition dynamics. Ecology 63, 621-626. doi: $10.2307 / 1936780$

Melillo, J. M., Butler, S., Johnson, J., Mohan, J., Steudler, P., Lux, H., et al. (2011). Soil warming, carbon-nitrogen interactions, and forest carbon budgets. Proc. Natl. Acad. Sci. U.S.A. 108, 9508-9512. doi: 10.1073/pnas.1018189108

Miltner, A., Bombach, P., Schmidt-Brücken, B., and Kästner, M. (2012). SOM genesis: microbial biomass as a significant source. Biogeochemistry 111, 41-55. doi: $10.1007 /$ s10533-011-9658-z

Morris, R. J. (2010). Anthropogenic impacts on tropical forest biodiversity: a network structure and ecosystem functioning perspective. Philos. Trans. R. Soc. B Biol. Sci. 365, 3709-3718. doi: 10.1098/rstb.2010.0273

Nadelhoffer, K. J., Boone, R. D., Bowden, R. D., Canary, J. D., Kaye, J., Micks, P., et al. (2004). "The DIRT experiment: litter and root influences on forest soil organic matter stocks and function. Chapter 15," in Forests in Time: The Environmental Consequences of 1000 Years of Change in New England, eds D. Foster, and J. Aber (New Haven, CT: Yale University Press), 300-315.

Pan, Y., Birdsey, R. A., Fang, J., Houghton, R., Kauppi, P. E., Kurz, W. A., et al. (2011). A large and persistent carbon sink in the world's forests. Science 333, 988-993. doi: 10.1126/science.1201609

Post, W. M., Izaurralde, R. C., West, T. O., Liebig, M. A., and King, A. W. (2012). Management opportunities for enhancing terrestrial carbon dioxide sinks. Front. Ecol. Environ. 10, 554-561. doi: 10.1890/120065

Preston, C. M., Nault, J. R., Trofymow, J. A., Smyth, C., and and, C. I. D. E.T., Working Group (2009). Chemical changes during 6 years of decomposition of 11 litters in some Canadian forest sites. Part 1. Elemental composition, tannins, phenolics, and proximate fractions. Ecosystems 12, 1053-1077. doi: 10.1007/s10021-009-9266-0

Rahman, M. M., Tsukamoto, J., Rahman, M. M., Yoneyama, A., and Mostafa, K. M. (2013). Lignin and its effects on litter decomposition in forest ecosystems. Chem. Ecol. 29, 540-553. doi: 10.1080/02757540.2013.790380

Rasse, D. P., Rumpel, C., and Dignac, M. F. (2005). Is soil carbon mostly root carbon? Mechanisms for a specific stabilisation. Plant Soil 269, 341-356. doi: 10.1007/s11104-004-0907-y

Sayer, E. J., Lopez-Sangil, L., Crawford, J. A., Bréchet, L. M., Birkett, A. J., Baxendale, C., et al. (2019). Tropical forest soil carbon stocks do not increase despite 15 years of doubled litter inputs. Sci. Rep. 9:18030. doi: 10.1038/s41598-019-54487-2

Smithwick, E. A. H., Harmon, M. E., Remillard, S. M., Acker, S. A., and Franklin, J. F. (2002). Potential upper bounds of carbon stores in forests of the Pacific Northwest. Ecol. Appl. 12, 1303-1317. doi: 10.1890/10510761(2002)012[1303:PUBOCS]2.0.CO;2

Soil Survey Staff (1999). Soil Taxonomy: A Basic System of Soil Classification for Making and Interpreting Soil Surveys, 2nd Edn. Washington, DC: Natural
Resources Conservation Service. U.S. Department of Agriculture Handbook 436 (PDF). United States Department of Agriculture; Naturel Resources Conservation Service.

Sollins, P., Kramer, M. G., Swanston, C., Lajtha, K., Filley, T., Aufdenkampe, A. K., et al. (2009). Sequential density fractionation across soils of contrasting mineralogy: evidence for both microbial- and mineralcontrolled soil organic matter stabilization. Biogeochemistry 96, 209-231. doi: 10.1007/s10533-009-9359-z

Sollins, P., Swanston, C., Kleber, M., Filley, T., Kramer, M., Crow, S., et al. (2006). Organic C and $\mathrm{N}$ stabilization in a forest soil: evidence from sequential density fractionation. Soil Biol. Biochem. 38, 3313-3324. doi: 10.1016/j.soilbio.2006.04.014

Sollins, P., Swanston, C., and Kramer, M. (2007). Stabilization and destabilization of soil organic matter - a new focus. Biogeochemistry 85, 1-7. doi: 10.1007/s10533-007-9099-x

Stewart, C. E., Plante, A. F., Paustian, K., Conant, R. T., and Six, J. (2008). Soil carbon saturation: linking concept and measurable carbon pools. Soil Sci. Soc. Am. J. 72, 379-392. doi: 10.2136/sssaj2007.0104

Sulman, B. N., Phillips, R. P., Oishi, A. C., Shevliakova, E., and Pacala, S. W. (2014). Microbe-driven turnover offsets mineral-mediated storage of soil carbon under elevated $\mathrm{CO}_{2}$. Nat. Clim. Chang. 4, 1099-1102. doi: 10.1038/ nclimate 2436

Talbot, J. M., and Treseder, K. K. (2012). Interactions among lignin, cellulose, and nitrogen drive litter chemistry-decay relationships. Ecology 93, 345-354. doi: 10.1890/11-0843.1

Talbot, J. M., Yelle, D. J., Nowick, J., and Treseder, K. K. (2012). Litter decay rates are determined by lignin chemistry. Biogeochemistry 108, 279-295. doi: 10.1007/s10533-011-9599-6

Valachovic, Y. S., Caldwell, B. A., Cromack, K. Jr., and Griffiths, R. P. (2004). Leaf litter chemistry controls on decomposition of Pacific Northwest trees and woody shrubs. Can. J. Forest Res. 34, 2131-2147. doi: 10.1139/x04-089

Wang, H., Boutton, T. W., Xu, W., Hu, G., Jiang, P., and Bai, E. (2015) Quality of fresh organic matter affects priming of soil organic matter and substrate utilization patterns of microbes. Sci. Rep. 5, 1-13. doi: 10.1038/ srep 10102

Winsome, T., Silva, L. C. R., Scow, K. M., Doane, T. A., Powers, R. F., and Horwath, W. R. (2017). Plant-microbe interactions regulate carbon and nitrogen accumulation in forest soils. For. Ecol. Manage. 384, 415-423. doi: 10.1016/j.foreco.2016.10.036

Wutzler, T., and Reichstein, M. (2013). Priming and substrate quality interactions in soil organic matter models. Biogeosciences 10, 2089-2103. doi: 10.5194/bg-10-2089-2013

Yano, Y., Lajtha, K., Sollins, P., and Caldwell, B. A. (2005). Chemistry and dynamics of dissolved organic matter in a temperate coniferous forest on andic soils: effects of litter quality. Ecosystems 8, 286-300. doi: 10.1007/s10021-0050022-9

Ziegler, S. E., Benner, R., Billings, S. A., Edwards, K. A., Philben, M., Zhu, X., et al. (2017). Climate warming can accelerate carbon fluxes without changing soil carbon stocks. Front. Earth Sci. 5, 1-12. doi: 10.3389/feart.2017. 00002

Conflict of Interest: The authors declare that the research was conducted in the absence of any commercial or financial relationships that could be construed as a potential conflict of interest.

Copyright (c) 2021 Pierson, Peter-Contesse, Bowden, Nadelhoffer, Kayhani, Evans and Lajtha. This is an open-access article distributed under the terms of the Creative Commons Attribution License (CC BY). The use, distribution or reproduction in other forums is permitted, provided the original author(s) and the copyright owner(s) are credited and that the original publication in this journal is cited, in accordance with accepted academic practice. No use, distribution or reproduction is permitted which does not comply with these terms. 